УДК 811.161.1'373.217(23)

DOI https://doi.org/10.24919/2308-4863/34-3-25

Нина НАГАЙЦЕВА, orcid.org/000-0001-8188-8141 кандидат филологических наук, профессор кафедры гуманитарных наук Национального технического университета «Харьковский политехнический институт» (Харьков, Украина)kgn.fmo@gmail.com

Юрий РОМАНОВ, orcid.org/0000-0002-7819-3119 кандидат филологических наук, доиент кафедры гуманитарных наук Национального технического университета «Харьковский политехнический институт» (Харьков, Украина) yu.aleks63@gmail.com

\title{
СЛУЖЕБНЫЕ ЧАСТИ РЕЧИ КАК НЕОТЬЕМЛЕМАЯ СОСТАВЛЯЮЩАЯ СИСТЕМЫ РКИ (РУССКОГО ЯЗЫКА КАК ИНОСТРАННОГО)
}

Статья посвящена компаративному анализу предлогов и союзов с точки зрения их частотности, значения, структуры, этимологии, особенностей функиионирования. Цель статьи - обоснование необходимости более глубокого и всестороннего изучения креативных и значительных по объёму служебных частей речи в курсе РКИ для формирования у обучаемых системных знаний, навыков и умений в этой области. При обучении иностранцев русскому языку мы более всего обращаем внимание на знаменательные части речи, составляющие фундамент языка, т.е. формируем системность в области грамматики знаменательных частей речи. Но лимь сформированная системность знаний и в области служебных частей речи позволяет сделать заключение о системности знаний обучаемого в области языка в иелом. Система служебных частей речи в русском языке чрезвычайно разветвлена, креативна, объёмна и сложна для самостоятельного усвоения. В русском языке предлоги, влияя на форму знаменательных слов, способны выражать самые разные объектно-обстоятельственные отношения в словосочетании и предложении; союзы, не влияя на форму слова, выражают синтаксические отношения между словоформами простого предложения, частями сложного предложения и отдельными предложениями; а абсолютно несамостоятельные частицы диктуют смысловые оттенки отдельным словам, словосочетаниям, предложениям. Сопоставление предлогов и союзов позволяет выявить их грамматические сходства и различия, анализ которых совершенно необходим при изучении языка. После основательной теоретической и практической работь над формированием навыков и умений по корректному использованию предлогов и союзов в простой устной коммуникации необходимо обратить внимание иностранных учащиихя и на потенциальные возможности этих служебных частей речи, раскрывающиеся в художественных текстах. Знание служебных частей речи необходимо учашимся для устной коммуникации, при чтении научных и художественных текстов, выполнении значительного количества грамматических упражнений; они актуальны и незаменимы для филологов, переводчиков, преподавателей РКИ.

Ключевые слова: предлоги, союзы, частицы, дискурс, русский как иностранный (РКИ). 
Ніна НАГАЙЦЕВА,

orcid.org/000-0001-8188-8141

кандидат філологічних наук,

професор кафедри гуманітарних наук

Національного технічного університету «Харківський політехнічний інститут»

(Харків, Україна)kgn.fmo@gmail.com

Юрій РОМАНОВ,

orcid.org/0000-0002-7819-3119

кандидат філологічних наук,

дочент кафедри гуманітарних наук

Національного технічного університету «Харківський політехнічний інститут» (Харків, Україна) yи.aleks63@gmail.com

\title{
СЛУЖБОВІ ЧАСТИНИ МОВИ ЯК НЕВІД'ЄМНИЙ СКЛАДНИК СИСТЕМИ РМІ (РОСІЙСЬКОї МОВИ ЯК ІНОЗЕМНОї)
}

\begin{abstract}
Статтю присвячено компаративному аналізу прийменників і сполучників з точки зору їх уживаності, значення, структури, етимології, особливостей функціонування. Мета статті - обтрунтувати необхідність більш глибокого і всебічного вивчення креативних і значних за обсягом службових частин мови в курсі РМІ для формування у студентів системних знань, навичок і умінь у цій галузі. Під час навчання іноземиів російської мови ми найбільше звертаємо увагу на знаменні частини мови, що становлять фундамент мови, тобто формуємо системність у изарині граматики знаменних частин мови. Але лите сформована системність знань також і службових частин мови дає можливість зробити висновок про системність знань мови загалом. Система службових частин мови в російській мові надзвичайно розгалужена, креативна, об 'ємна і складна для самостійного засвоєння. У російській мові прийменники, впливаючи на форму знаменних слів, здатні висловлювати найрізноманітніші об'єктно-обставинні відносини в словосполученні й реченні; сполучники, не впливаючи на форму слова, виражають синтаксичні відносини між словоформами простого речення, частинами складного речення й окремими реченнями; а абсолютно несамостійні частки диктують смислові відтінки окремим словам, словосполученням, реченням. Зіставлення прийменників і сполучників дає можливість виявити їхні граматичні подібності та відмінності, аналіз яких абсолютно необхідний у вивченні мови. Після трунтовної теоретичної і практичної роботи над формуванням навичок і вмінь щзодо коректного використання прийменників $і$ сполучників у простій усній комунікації необхідно звернути увагу іноземних учнів $і$ на потенційні можливості ичих службових частин мови, щчо розкриваються в художніх текстах. Знання службових частин мови необхідні учням для усної комунікації, в читанні наукових і художніх текстів, виконанні значної кількості граматичних вправ; вони актуальні і незамінні для філологів, перекладачів, викладачів РМI.
\end{abstract}

Ключові слова: прийменники, сполучники, частки, дискурс, російська як іноземна (РМI).

Nina NAGAITSEVA,
orcid.org/000-0001-8188-8141
Candidate of Philological Sciences,
Professor at the Department of Humanities
National Technical University "Kharkiv Polytechnic Institute"
(Kharkiv, Ukraine) kgn.fmo@gmail.com
Yuri ROMANOV,
orcid.org/0000-0002-7819-3119
Candidate of Philological Sciences,
National Technical University "Kharkiv Polytechnic Institute”
(Kharkiv, Ukraine) yu.aleks63@gmail.com

\section{AUXILIARY PARTS OF SPEECH AS A CONSTITUENT OF RFL (RUSSIAN AS A FOREIGN LANGUAGE) SYSTEM}

This article is devoted to the comparative analysis of prepositions and conjunctions in terms of their frequency, meaning, structure, etymology, and ways of functioning. The purpose of the article is to substantiate the need for a deeper and more comprehensive study of the creative and significant in volume auxiliary parts of speech during RFL course for the formation of learners'systemic knowledge, skills and abilities in this field. When teaching Russian to foreigners, we 
most of all pay attention to content words that form the foundation of the language, i.e. we form a systematic grammar of content words. But only the formed systematic knowledge of auxiliary parts of speech allows for making a conclusion about the learner's systematic knowledge of the language as a whole. The system of auxiliary parts of speech in Russian is extremely ramified, creative, voluminous, and difficult for independent learning. In Russian, prepositions influencing the form of notional words are capable of expressing a variety of object-adverbial relations in a phrase and a sentence; conjunctions, without affecting the form of a word, express syntactic relations between word forms of a simple sentence, parts of a complex sentence, and separate sentences; and absolutely non-independent particles dictate shades of meaning to separate words, phrases, sentences. Comparison of prepositions and conjunctions makes it possible to identify their grammatical similarities and differences the analysis of which is absolutely necessary when learning a language. After thorough theoretical and practical work on the formation of skills and abilities for the correct use of prepositions and conjunctions in simple oral communication, it is necessary to draw the attention of international students to the potential capabilities of these auxiliary parts of speech revealed in literary texts. Knowledge of the auxiliary parts of speech is necessary for oral communication, while reading scientific and artistic texts, performing a significant amount of grammar exercises; it is relevant and indispensable for philologists, translators, and RFL teachers.

Key words: prepositions, conjunctions, particles, discourse, Russian as a foreign language (RFL).

Постановка проблемы. При обучении русскому языку как иностранному (далее - РКИ) учащихся разных категорий наибольшее внимание уделяют, как правило, знаменательным частям речи, составляющим грамматическое «древо» языка, его фундамент (падежная и видо-временная системы; слово-, формообразование и сочетаемость знаменательных частей речи; глаголы движения и их функционирование), таким образом, формируют системность в области грамматики знаменательных частей речи.

Однако только сформированность системных знаний и в области служебных частей речи позволяет сделать заключение о системности знаний и языковой компетенции учащегося в целом.

Анализ исследований. О служебных частях речи, их сущности, значимости и особенностях в разное время писали многие исследователи (Бондаренко, 1961; Виноградов, 1972; Всеволодова, Владимирский, 2008; Нагайцева, 2015, 2016, 2017; Нагайцева, Романов, 2017, Nagaitseva, Romanov, 2016, 2018; Потебня, 1985; Прияткина, 1977; Черкасова, 1967, 1973; Шахова, 2014).

На современном этапе отмечается важная роль служебных частей речи при передаче экспрессивности, эмоциональности, оценочности высказывания, поскольку «свободное владение языком предусматривает понимание не просто смысла высказывания, но и того отношения к предмету речи, которое говорящий хочет передать адресату» (Смирнова, 2011: 59); исследуется смыслообразующий потенциал служебных частей речи в поэтических текстах (Муратова, 2012); осуществляются попытки лексикографического описания служебных слов в поэтических произведениях (Шипулина, 2012); практику преподавания РКИ отражают учебные пособия (Ильина, Иванова. 2013; Нагайцева, 2015, 2016, 2017) (данные пособия описывают структуру служебных частей речи, раскрывают их семантику, демонстрируют сино- нимию, антонимию и омонимию; помимо теоретической части содержат сотни тренировочных и коммуникативных упражнений, обобщающие таблицы, другие полезные материалы).

Цель статьи - обоснование необходимости более глубокого и всестороннего изучения креативных и значительных по объёму служебных частей речи в курсе РКИ для формирования системных знаний в этой области.

Изложение основного материала. Сформированная системность в области только грамматики знаменательных частей речи у самых прилежных и способных иностранных учащихся может поставить их на один уровень с преподавателяминосителями языка, если предъявить первым и вторым общеизвестное предложение-абракадабру: Гло́кая ку́здра ште́ко будлану́ла бокра́ и курдя́чит бокрёнка, совершенно прозрачное по грамматической структуре (субъект ж.р. с согласованным атрибутом; предикаты прошедшего (с примыкающим адвербиальным атрибутом) и настоящего времени, координирующиеся с субъектом; прямые одушевлённые объекты м.р. (один из которых оформлен с уменьшительным суффиксом -ёнк-)) и абсолютно «заиксованное» в смысловом плане, поскольку наполнено несуществующей в русском языке лексикой, впрочем, кроме союза $\boldsymbol{u}$ (соединяющего однородные члены предложения).

Таким образом, определение знаменательных частей речи как лексико-грамматических групп принципиально важно, ведь семантическое содержание лексики именно знаменательных частей речи глобально покрывает потребности воспринимаемого и порождаемого дискурса.

Действительно, грамматические потенции и особенности знаменательных частей речи - это ядро языка, его альфа и омега, и необходимость глубокого погружения в эту его часть на базе лексики не вызывает сомнения, методически целесообразна и абсолютно обязательна для выхода 
во все виды речевой деятельности (далее - РД): чтение, письмо, говорение, аудирование. Однако даже длительное и серьёзное изучение значения, форм и особенностей функционирования только знаменательных частей речи не означает качественно полного освоения языка, поскольку лишь дискурсивное воплощение РД свидетельствует о степени познания русского языка, чему в значительной мере способствует системность знаний и в области служебных частей речи.

Значимость служебных частей речи, несомненно, недооценена (что и отражено в Программах по РКИ, за редким исключением (Программа, 2014)); лингвометодические трудности, возникающие при отборе предлогов и презентации их в нормативно-методических документах базового уровня владения РКИ, рассмотрены недостаточно (Виноградова, Клобукова, 2017), хотя они играют важнейшую роль как в структурировании синтаксических единиц всех уровней (словосочетание простое предложение - сложное предложение), так и в организации наиболее крупной из структурно-семантических единиц членения текста сложного синтаксического целого.

Почему же для абсолютно адекватного восприятия / порождения текста столь важны служебные части речи?

1. Текст создаётся целым рядом разноуровневых средств, содержащих элементы языковой когерентности.

2. Корректные рецепция и продукция текста должны быть обеспечены средствами плавного перехода от предложения к предложению абзаца.

3. При интерпретации текста также должны учитываться средства связи слов и словосочетаний внутри предложения.

4. Стилистическое разграничение сфер употребления предложений в тексте также должно быть учтено.

Эти и другие лингвистические факторы, лежащие на поверхности дискурсной проблематики, не могут быть решены без участия служебных частей речи.

К служебным частям речи в русском языке относятся предлоги, союзы и частицы, которые не имеют категориального значения, форм изменения, но «играют громадную организующую роль» (Виноградов, 1972: 521), придавая предложению структурно-семантическую определённость и законченность. Кроме того, знания о знаменательных частях речи не могут быть использованы абсолютно аутентично без знаний о служебных частях речи, которые по языкам существенно разнятся как по значению, так и по форме, функциям и объёму единиц.
Система служебных частей речи в русском языке чрезвычайно разветвлена, креативна, объёмна и сложна для самостоятельного усвоения.

Так, в русском языке предлоги, влияя на форму знаменательных слов, способны выражать самые разные объектно-обстоятельственные отношения в словосочетании и предложении; союзы, не влияя на форму слова, выражают синтаксические отношения между словоформами простого предложения, частями сложного предложения и отдельными предложениями; а абсолютно несамостоятельные частицы диктуют смысловые оттенки отдельным словам, словосочетаниям, предложениям.

Кроме того, количество служебных частей речи само по себе значительно: союзов - 110 , предлогов - 141, частиц - 149 (Обратный словарь русского языка, 1974), а частотность их использования впечатляет: ср.: союзы: $\boldsymbol{a}-10719$, ито 13 125, $\boldsymbol{u}$ - 36 266; предлоги: $\boldsymbol{c}$ - 12 975, на - 17262 ,

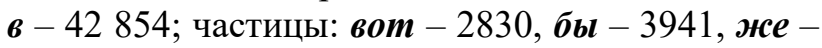
4037 (Частотный словарь русского языка, 1977); следует также учитывать многозначность и непрерывное живое пополнение служебных частей речи.

Поэтому корректность или некорректность использования иностранцем в дискурсе служебных частей речи служит маркером его уровня владения языком. Сопоставление предлогов и союзов позволяет выявить их грамматические сходства и различия. В частности, у них немало сходств.

1. Это неизменяемые слова.

2. Они не имеют собственно лексического значения.

3. Предлоги и союзы способны выражать определённые отношения.

4. Они не называют ничего «вещественного». Предлоги и союзы не несут в себе значения конкретных типов синтаксических отношений (временны́х, пространственных, условных и др.).

5. Функционально они не являются членами предложения.

6. По своей структуре предлоги и союзы могут быть простыми и составными, причём морфологическая структура простых предлогов и союзов не членится на морфемы, но «корни» служебных слов, в частности предлогов, могут совпадать с префиксами знаменательных слов, например, префиксальных глаголов: ср.: вбежать в дом; написать на листке; стереть с доски; доехать до Киева; оттолкнуть от себя и др. (закон сингармонизма).

7. По значению простые служебные части речи обычно многозначны $(\boldsymbol{b} ; \boldsymbol{u})$, а сложные - однозначны (в случае чего? потому что).

8. Для служебных частей речи, как и для знаменательных, характерны синонимия (вследствие чего? = в результате чего?; потому что $=$ так 
как), антонимия (над $\neq$ под чем?; после того как $\neq$ перед тем как), омонимия.

9. В русском языке наравне с современными функционируют и устаревшие предлоги (перед / пред, через / чрез, среди / средь) и союзы (дабы = чтобы, нежели = чем, ежели =если).

10. Частотность предлогов и союзов - от сотен до тысяч употреблений (см. выше).

11. Предлоги и союзы полностью лишены оценочности, эмоционально-экспрессивной окрашенности.

12. Есть явный параллелизм грамматического развития союзов и предлогов.

13. Первообразные предлоги и союзы унаследованы русским языком из общеславянского фонда, например: предлоги: $\boldsymbol{в}, \boldsymbol{\kappa}, \boldsymbol{\mu a}, \boldsymbol{c} ;$ союзы: $\boldsymbol{a}, \boldsymbol{u}, \boldsymbol{\mu o}$

Часто граница между знаменательными и служебными частями речи не определена (особенно у частиц).

Но между предлогами и союзами есть и существенные различия.

1. Предложно-падежная форма уже́ является полноценным членом предложения; союзные слова, несущие значения знаменательных и служебных частей речи, - тоже: который, какой, где, куда, откуда и др. Но не союзы!

2. Грамматическое значение предлогов - предложное значение, а грамматическое значение союзов - общее указание на связь (сочинительную или подчинительную).

3. Влияние предлогов на последующую форму слов и невлияние союзов на форму слов.

4. Предлоги выражают отношения синтаксической зависимости предложных форм от определенных слов. Союзы же выражают различные синтаксические отношения функционально однородных единиц.

5. Союзы не переходят в «префиксы», как предлоги.

6. В отличие от предлогов, союзы не соотносятся с грамматическими формами (ср.: брат с сестрой $\neq$ брат и сестра).

7. Союз, в отличие от предлога, функционирует не сам по себе, а в сочетании единиц.

8. Предлоги влияют на именную форму (связь с падежными формами), а союзы - на глагольную форму (связь с видо-временны́ми формами).

9. Позиция предлогов в основном перед словоформой; союзов а) сочинительных - между первой и второй единицей, перед каждой из них; б) подчинительных - и перед, и после, и в каждой части предложения.

10. Производные предлоги генетически связаны с отсубстантивными (во время чего?); отадъ- етивными (подобно чему?), отадвербиальными (после чего?), глагольными словами (несмотря на что?), а многие производные союзы - с предлогами (после того как, вместо того чтобы).

11. Устаревших предлогов мало (конь о четьрёх ногах; там о заре прихльнут волны на брег...), союзов - много, и они достаточно активны, особенно в художественных текстах. Ср.: али = или, кабы = если бы, коли =если, ежели =если, дабы = чтобы и др.

12. Простые союзы потенциально продуцируют частицы ( $\boldsymbol{u}, \boldsymbol{a}, \boldsymbol{л})$, а составные союзы мотивируются предлогами (после чего? - после того как).

13. Следует отметить и дифференциацию внутри союзов, на которую до́лжно обратить внимание уже при их первичной презентации: это существенная разница в функциях союзов, соединяющих а) предложения; б) отдельные слова/словосочетания. В первом случае отношения, выраженные союзами, шире, а во втором - есть даже частичный параллелизм со значением предлогов (временно́е, причинное, целевое, сравнительное и др.) (Виноградов, 1972: 553).

14. Наблюдается принципиальное различие между первообразными и новыми союзами. В последнем случае видим явный параллелизм грамматического развития между союзами и предлогами.

15. Существует важное несходство между сочинительными и подчинительными союзами в том, какие единицы они связывают и каково их формальное устройство.

Сочинительные союзы соединяют синтаксические единицы одного уровня, функционально и семантически аналогичные. Подчинительные союзы участвуют собственным значением в формировании номинативного и функционально-синтаксического значения предикативных единиц.

Семантическая зависимость сочинительных и подчинительных союзов обусловлена их структурой. Простые морфологически неделимые союзы «переобременены значениями», «слабость лексического и морфологического веса таких союзов компенсируется семантико-синтаксической нагруженностью» (Виноградов, 1972: 555).

Лишь повтор сочинительного союза ограничивает круг его значений: возникают повторные соединительные, перечислительные, разделительные, противительные и др. союзы. Ср.: $\boldsymbol{u} / \boldsymbol{u}$ ...и, или / или ...или:

И сердие бьётся в упоенье,

И для него воскресли вновь

И божество, и вдохновенье,

И жизнь, и слёзы, и любовь.

А. Пушкин 
Потенциальная же многозначность простых подчинительных союзов нивелируется их соединением с предложными сочетаниями. Ср. способность простого союза что выражать изъяснительные, определительные, временны́е, сравнительные, причинные, количественные и др. значения, а в сложной структуре - только причинное значение (в силу того что) или только следственное значение (в результате того что), т.е. образование составных подчинительных союзов на базе простых - один из обычных способов конкретизации значения последних.

После основательной теоретической и практической работы над формированием навыков и умений по корректному использованию предлогов и союзов в простой устной коммуникации, корректному восприятию их в письменных учебных текстах, а также при их продуцировании необходимо обратить внимание инолингвов и на потенциальные возможности этих служебных частей речи и особенности их функционирования в художественных текстах.

1. Использование при однородных членах предложения:

- одного предлога / союза для всего ряда: $O H$ любит бутерброды с маслом, сыром и колбасой;

-повторяющихся предлогов/ союзов в ряду: ср.:

предлог: В кабаках, в переулках, в извивах,

$\boldsymbol{B}$ электрическом сне наяву

Я искал бесконечно красивых

И бессмертно влюбленных в молву. А. Блок союз:

Колокольчик звонко плачет

И хохочет, и визжит.

П. Вяземский

- разных предлогов с целью расширения информационного поля:

Серебристая гладь, серебристая даль

Надо мной, предо мною, за мною...

И. Анненский

- соединение однородных членов попарно: ср.:

В счастье игоре, в радости и болиони были вместе.

- выделение графическое:

Вверx-

флаг!

Рвань -

встань!

Bpaz -

ляг!

День -

дрянь!

За хлебом!

За миром!

За волей!
2. Повторение предлога в одном словосочетании: Вот в сочельник в самый, в ночь

Бог даёт иарище дочь. А. Пушкин

3. Нетипичная постпозитивная позиция: ср.:

предлог: Поэзия -

та же добыча радия <...>

Изводишь

единого слова ради

тысячи тонн

словесной руды. $\quad$ В. Маяковский

союз:

Сам себя ты, грешник, мучишь;

Убирайся, иел пока. А. Пушкин

4. Дистанционное расположение предлога и именной формы:

...наши прадеды молятся

За в бога неверящих внуков своих

К. Симонов

5. Использование предлога как знаменательной единицы (без именной формы) при сохранении аутентичной семантической компоненты:

И сльишит

шепот гордый

вода

$u$ nod,

u над:

"Через четыре

года

здесь

будет

город-сад!». $\quad$ В. Маяковский

6. В ближайшем контексте использование в предложно-падежных формах антонимичных предлогов:

Я за положительность

и против инцидентов,

которые

вредят

служебной карьере. $\quad$ В. Маяковский

7. Использование предлогов

- с устаревшим управлением:

Сквозь слёз, не видя ничего

Татьяна слушала его [Онегина]

Ср.: сквозь слёзы.

А. Пушкин

Повелел он [иарь] схватить удалова купияа

И привесть его пред лицо своё.

М. Лермонтов

Ср.: перед лицом своим.

- устаревших предлогов, синонимичных современным:

Про тебя мне шептали кусты

В белоснежных полях... 
Ср.: о тебе.

8. Союз

- закрывает ряд однородных членов:

Онегин шка́фы отворил;

В одном намел тетрадь расхода,

В другом наливок иельй строй,

Кувшины с яблочной водой

И календарь осьмого года.

А. Пушкин

- соединяет две и более простые предикативные единицы: Закончился дождь, и мы пошли домой.

- соединяет два и более однотипных сложноподчинённых предложения:

Мечта! Если мелко мечтать и лениво, -

мечта остаётся туманом и пьллюю,

а если мечтать в состоянье порыва, она непременно становится былью.

С. Васильев

9. Союзы присоединяют вставные слова, словосочетания, предложения:

И каждый вечер, в час назначенный

(Иль это только снится мне?),

Девичий стан, шелками схваченный,

В туманном движется окне.

А. Блок

10. Бессоюзное и союзное соединение однородных членов в одном предложении:

Ну́в них они [обезьяны] кувыркаться, кататься,

И кутаться, и завиваться.

И. Крылов

11. Соединение сочинительных и подчинительных союзов в одном предложении:

«И деньги есть?»- «Ну, нет,

Хоть лишних не бывает,

Зато нет лишних и затей».

И. Крылов

12. Присоединение придаточных предложений одним и тем же союзом / союзным словом:

А мыс споём о родине,

С которой столько связано,

С которой столько пройдено

Хорошего и разного! И. Уткин

13. Присоединение придаточного предложения через «куст» союзов / союзных слов: Скажи, куда, к кому и зачем ты идёшь.

14. Присоединение придаточных предложений через «куст» одинаковых конструкций с различными союзами / союзными словами:

Tын не спрашивай, не распытывай,

Умом-разумом не раскидывай:

Как люблю тебя, почему люблю,

И за что люблю,

И надолго ли?

А.К. Толстой
15. Парцелляция конструкций с союзами / союзными словами:

Звенящая над веком

да здравствует

любовь!

Которой всё

дано:

и муки,

и горенье! Р. Рождественский

16. Использование только одной части двухместного союза (устаревшее):

Она ласкаться не умела

К отиу, ни к матери своей. А. Пушкин

Ср.: ни к отиу, ни к матери.

17. Использование союзов в нетрадиционном для современного русского языка значении:

Мать как-то спокойно сидела,

Казалось, не веря ещё и теперь,

Чтоб дочка уехать посмела.

Ср.: Что дочка уехать посмела.

Н. Некрасов

Ещё более глубокого включения иностранного реципиента в потенциальные мультивозможности русского языка требует, например, способность служебных частей речи как бы «ткать» поэтическую ткань, увеличивая вес, роль, значимость этих слов внутри стиха за счёт их выделения, выдвижения в самостоятельную строку в «ломаной» структуре рифмованного текста.

Такое усложнение графической композиции приводит, с одной стороны, к определённой деформации семантического содержания дискурса, с другой стороны, к визуальному маркированию текста, связанного с определённым автором-творцом (вспомним хотя бы лингвистические опыты декадентов), а с третьей - к усилению фонетикоакустического воздействия на реципиента за счёт «переплетающихся» аллитераций и ассонансов, построенных на слоговом взаимодействии знаменательных и служебных частей речи. Ср.:
$\boldsymbol{y}_{-}$
лииа.
Лйuุa
[Утро]
$\boldsymbol{y}$
догов
годов
рез-
Угрюмый дождь скосил
ue.
पe-
pes
глаза́.
$\boldsymbol{A}$ за́
решёткой
чёткой
железной мысли
проводов -
железных коней <... н неё
прыгнули первые кубы. встающих звёзд
В. Маяковский
легко оперлись ноги.
В. Маяковский 
Выводы. Следует отметить, что работа над служебными частями речи требует вдумчивости и времени, чтобы решить задачу формирования устойчивых навыков и умений в активной устной коммуникации, при чтении научных и художественных текстов, выполнении значительного количества специальных упражнений, характеризующихся как разнообразием представленных предлогов и союзов, так и их функционированием в живой речи. Соображения по презентации русских частиц и их особенностям в рамках РКИ освещены в отдельной работе (Nagaitseva,
Romanov, 2018). Исходя из вышеизложенного, следует сделать принципиальный вывод о безусловной обязательности более основательного изучения служебных частей речи с целью формирования подлинной и полной системности в области грамматики русского языка: служебные части речи являются таковыми в архитектонике текста, а в семантико-стилистическом плане вполне знаменательно влияют на дискурс. Кроме того, такие знания особенно актуальны и незаменимы для филологов, переводчиков и преподавателей РКИ.

\section{СПИСОК ИСПОЛЬЗОВАННЫХ ИСТОЧНИКОВ}

1. Бондаренко В. С. Предлоги в современном русском языке. Москва : Учпедгиз, 1961.75 с.

2. Виноградов В. В. Русский язык: Грамматическое учение о слове. Москва : Высшая школа, 1972. 601 с.

3. Виноградова Е. Н., Клобукова Л. П. Лингводидактические проблемы описания предлогов на базовом уровне общего владения русским языком как иностранным. Мир русского слова. 2017. № 4. С. 87-99.

4. Всеволодова М. В., Владимирский Е. Ю. Способы выражения пространственных отношений в современном русском языке. Москва : ЛКИ, 2008. 288 с.

5. Ильина С. А., Иванова И. С. Учебное пособие «Начинаем учить предлоги и союзы. Предложно-падежные и союзные конструкции в речи». Вестник Российского университета дружбы народов. Серия: Русский и иностранные языки и методика их преподавания. 2013. № 4. С. 124-128.

6. Муратова Е. Ю. Роль служебных частей речи в формировании художественных смыслов поэтического текста. Язык и культура. 2012. № 2. С. 53-61.

7. Нагайцева Н. И. Предлоги : учеб. пособ. для иностранцев. Харьков : НТУ «ХПИ», 2015. 268 с.

8. Нагайцева Н. И. Союзы : учеб. пособ. для иностранцев. Харьков : НТУ «ХПИ», 2016. 292 с.

9. Нагайцева Н. И. Частицы : учеб. пособ. для иностранцев. Харьков : НТУ «ХПИ», 2017. 194 с.

10. Нагайцева Н. И., Романов Ю. А. Предлог в системе обучения РКИ. Проблемы и перспективы языковой подготовки иностранных студентов : материалы ХІІ Междунар. науч.-практ. конф. Харьков : ХНАДУ, 2017. С. 118-123.

11. Обратный словарь русского языка / гл. ред. М. В. Лазовая. Москва : Сов. энциклопедия, 1974. 944 с.

12. Потебня А. А. Из записок по русской грамматике : Глагол. Местоимение. Числительное. Предлог : в 4 т. Москва : Просвещение, 1985. Т. 4. 287 с.

13. Прияткина А. Ф. Союзы в простом и сложном предложении : учеб. пособ. по спецкрусу для студентов-заочников филол. факультетов гос. университетов. Москва : Изд-во МГУ, 1977. 88 с.

14. Программа по русскому языку для студентов-иностранцев основных факультетов высших учебных заведений Украины III-IV уровней аккредитации / Н. И. Нагайцева и др. Харьков, 2014. 60 с.

15. Смирнова Л. Г. Взвесим все за и против. Служебные слова с оценочными коннотациями в русском языке. Русский язык за рубежком. 2011. № 1. С. 58-63.

16. Частотный словарь русского языка / под ред. Л. Н. Засориной. Москва : Русский язык, 1977. 936 с.

17. Черкасова Е. Т. Переход полнозначных слов в предлоги. Москва : Наука, 1967. 280 с.

18. Черкасова Е. Т. Русские союзы неместоименного происхождения: пути и способы их образования. Москва : Наука, 1973. $221 \mathrm{c}$.

19. Шахова Е. М. Возможность репрезентации действительности при помощи предложно-падежных форм имени, выражающих языковой смысл «пространство». Культура народов Причерноморья. 2014. № 267. С. 184-188.

20. Шипулина Г. И. Лексикографическое описание служебных слов в поэзии Сергея Есенина. Современное есениноведение. 2012. № 22. С. 65-73.

21. Nagaitseva N., Romanov Yu. Particles as a touchstone to determine the level of international students' Russian language proficiency. Науковий вісник Міжнародного гуманітарного університету. Серія «Філологія». 2018. № 36 . Т. 1. C. $108-110$.

22. Nagaitseva N., Romanov Yu. Preposition as a grammatical marker of language peculiarities. Науковий вісник Міжнародного гуманітарного університету. Сер. «Філологія». 2016. № 23. Т. 1. С. 140-142.

\section{REFERENCES}

1. Bondarenko V. S. Predlogi v sovremennom russkom yazyke [Prepositions in modern Russian]. M.: Uchpedgiz, 1961. 75 p. [in Russian]

2. Vinogradov V. V. Russkiy yazyk: Grammaticheskoe uchenie o slove [Russian: Grammar study about word]. M.: Vysshaya shkola, 1972. 601 p. [in Russian].

3. Vinogradova E. N., Klobukova L. P. Lingvodidakticheskie problemy opisaniya predlogov na bazovom urovne obshchego vladeniya russkim yazykom kak inostrannym [Linguodidactic problems of description of prepositions at the basic level of general knowledge of Russian as a foreign language]. Mir russkogo slova. 2017. № 4. pp. $87-99$ [in Russian]. 
4. Vsevolodova M. V., Vladimirskiy E. Yu. Sposoby vyrazheniya prostranstvennykh otnosheniy v sovremennom russkom yazyke [Ways of expressing spatial relationships in modern Russian]. M.: LKI, 2008. 288 p. [in Russian].

5. Il'ina S. A., Ivanova I. S. Uchebnoe posobie "Nachinaem uchit' predlogi i soyuzy. Predlozhno-padezhnye i soyuznye konstruktsii v rechi" [Study guide "We begin to learn prepositions and conjunctions. Prepositional-nominal and conjunction constructions in speech"]. Vestnik Rossiyskogo universiteta druzhby narodov. Seriya: Russkiy i inostrannye yazyki i metodika ikh prepodavaniya. 2013. № 4. pp. 124-128 [in Russian].

6. Muratova E. Yu. Rol' sluzhebnykh chastey rechi v formirovanii khudozhestvennykh smyslov poeticheskogo teksta [Role of auxiliary parts of speech in the formation of artistic meanings of a poetic text]. Yazyk i kul’tura. 2012 . № 2. pp. 53-61 [in Russian].

7. Nagaytseva N. I. Predlogi: ucheb. posob. dlya inostrantsev [Prepositions: A study guide for international students]. Kharkov: NTU "KhPI", 2015. 268 p. [in Russian].

8. Nagaytseva N. I. Soyuzy: ucheb. posob. dlya inostrantsev [Conjunctions: A study guide for international students]. Kharkov: NTU "KhPI", 2016. 292 p. [in Russian].

9. Nagaytseva N. I. Chastitsy: ucheb. posob. dlya inostrantsev [Particles: A study guide for international students]. Kharkov: NTU “KhPI”, 2017. 194 p. [in Russian].

10. Nagaytseva N. I., Romanov Yu. A. Predlog v sisteme obucheniya RKI [Preposition in the system of RFL teaching]. Problemy i perspektivy yazykovoy podgotovki inostrannykh studentov: Materialy XII Mezhdunar. nauch.-prakt. konf. Khar'kov: KhNADU, 2017. pp. 118-123 [in Russian].

11. Obratnyy slovar' russkogo yazyka [Reverse dictionary of the Russian language] / gl. red. M. V. Lazova. M.: Sov. entsiklopediya, 1974. 944 p. [in Russian].

12. Potebnya A. A. Iz zapisok po russkoy grammatike: v 4 t. Glagol. Mestoimenie. Chislitel'noe. Predlog [From notes on Russian grammar: in 4 volumes. Verb. Pronoun. Numeral. Preposition.]. M.: Prosveshchenie, 1985. T. 4. 287 p.

13. Priyatkina A. F. Soyuzy v prostom i slozhnom predlozhenii: ucheb. posob. po spetskrusu dlya studentov-zaochnikov filol. fakul'tetov gos. universitetov [Conjunctions in a simple and complex sentence: a study guide on a special course for correspondence students of philological faculties of state universities.]. M.: Izd-vo MGU, 1977. 88 p.

14. Programma po russkomu yazyku dlya studentov-inostrantsev osnovnykh fakul'tetov vysshikh uchebnykh zavedeniy Ukrainy III-IV urovney akkreditatsii [Program on the Russian language for international students of main faculties of higher educational institutions of Ukraine of III-IV levels of accreditation] / Nagaytseva N. I., Snegurova T. A., Chernyavskaya S. N. et al. Khar'kov, 2014. 60 p. [in Russian].

15. Smirnova L. G. Vzvesim vse za i protiv. Sluzhebnye slova s otsenochnymi konnotatsiyami v russkom yazyke [Pros and cons. Auxiliary words with evaluative connotations in Russian]. Russkiy yazyk za rubezhom. 2011. № 1. pp. 58-63 [in Russian].

16. Chastotnyy slovar' russkogo yazyka [Frequency dictionary of the Russian language] / pod red. L. N. Zasorinoy. M.: Russkiy yazyk, 1977. 936 p. [in Russian].

17. Cherkasova E. T. Perekhod polnoznachnykh slov v predlogi [Transition of full-valued words to prepositions]. M.: Nauka, 1967. 280 p. [in Russian].

18. Cherkasova E. T. Russkie soyuzy nemestoimennogo proiskhozhdeniya: puti i sposoby ikh obrazovaniya [Russian conjunctions of non-pronoun origin: ways and means of their formation]. M.: Nauka, 1973. 221 p. [in Russian].

19. Shakhova E. M. Vozmozhnost' reprezentatsii deystvitel'nosti pri pomoshchi predlozhno-padezhnykh form imeni, vyrazhayushchikh yazykovoy smysl "prostranstvo" [Possibilities of reality representation with the help of caseprepositional forms of the names which express language meaning “area”]. Kul’tura narodov Prichernomor’ya. 2014. № 267. pp. 184-188 [in Russian].

20. Shipulina G. I. Leksikograficheskoe opisanie sluzhebnykh slov v poezii Sergeya Esenina [Lexicographic description of auxiliary words in the poetry of Sergei Yesenin]. Sovremennoe eseninovedenie. 2012. № 22. pp. 65-73 [in Russian].

21. Nagaitseva N., Romanov Yu. Particles as a touchstone to determine the level of international students' Russian language proficiency. Naukoviy visnik Mizhnarodnogo gumanitarnogo universitetu. Seriya "Filologiya”. 2018. № 36 . T. 1. pp. 108-110.

22. Nagaitseva N., Romanov Yu. Preposition as a grammatical marker of language peculiarities. Naukoviy visnik Mizhnarodnogo gumanitarnogo universitetu. Ser. "Filologiya". 2016. № 23. T. 1. pp. 140-142. 